\title{
Guardians on Guardianship: Factors affecting the Willingness to Supervise, the Ability to Detect Potential Offenders \& the Willingness to Intervene
}

\section{Danielle M. Reynald}

\begin{abstract}
Within criminology, much attention has been given to the processes of offending and victimization, but comparatively few studies have focused on the processes underlying guardianship. The current study turns the spotlight towards the capable guardian as the critical actor within the crime event model with the power to prevent crime. This study interviews residential guardians to examine key factors that render them capable of disrupting opportunities for crime. Results reveal three critical dimensions of capable guardianship at micro-places: 1) the willingness to supervise, 2) the ability to detect potential offenders, and 3) the willingness to intervene when necessary.
\end{abstract}

\section{Introduction}

Routine Activity Theory \& the Capable Guardian

From the situational crime prevention perspective, the capable guardian plays a decisive role in the crime event model proposed by routine activity theory, as the actors who take up the responsibility of being the ultimate protectors and defenders of any target of crime- be it people or property. Routine activity theory explains that a crime can only occur in the absence of a capable guardian, as it leaves a suitable target unprotected against a motivated offender when they come together in time and space (Cohen \& Felson, 1979). In this way, guardians can be viewed as control agents within the routine activity theory of crime (Felson, 2006). Current developments in routine activity theory highlight the various roles assumed by the actors who are responsible for crime control, of which guardians represent just one. These roles have been expanded to include handlers who control potential offenders, and managers who control places (Eck, 1994). In this way, developments in routine activity theory point to the differential mechanisms that may come into play for those who exercise control over areas, smaller micro-places and individual people. Felson (1995) highlights varying levels of responsibility that accompany these roles, suggesting that guardians are likely to assume personal 
responsibility for the residential places that they belong to, and for targets which belong to, or are intimately connected with them.

Results from several empirical studies that utilize very different methodologies have consistently shown that capable guardianship is indeed a critical determinant of victimization. Studies that focus on guardianship either at the individual or aggregate level, or both, have found support for the negative relationship between guardianship and the risk of burglary victimization (eg. Wilcox et. al, 2007; Coupe \& Blake, 2006; Wilcox Rountree et. al, 1994; Garofalo \& Clarke, 1992; Miethe \& Meier, 1990). Miethe et. al (1987) reported that individuals who spend most of their time away from home, particularly during the night, suffered a relatively greater risk of having their property victimized. Miethe \& McDowall's (1993) contextual analysis also revealed evidence to support the conclusion that lower levels of guardianship significantly increase the risk of burglary for residents in middle- and upper-class areas.

Taken together, the results from these studies confirm the importance of guardianship as a mechanism through which crime can be prevented at place. What remains ambiguous, however, are the underlying processes that enable capable guardianship. As Miethe et. al (1987) explain, the weight and importance of capable guardianship requires more focused theoretical attention. In an observational study of guardianship in action, Reynald (2009) found that property crime was significantly lower at households with a higher intensity of directly observable guardianship during the day-time. In this way, the study revealed that: (1) the intensity of guardianship available at micro-places can be reliably and validly measured through direct observation; and (2) in addition to availability, guardianship intensity is also the product of actual monitoring by available guardians, and intervention when necessary. One of the major voids that still exists in the literature on guardianship, however, is how guardians make fundamental judgments or decisions that are critical to situational crime prevention. The current paper provides some insight into this previously neglected dimension of guardianship.

\section{Beyond Availability: Guardianship \& the ability to identify potential offenders}




\section{The Role of Context}

One of these innate judgments is how guardians distinguish between potential offenders and benevolent users of space. Roncek (1981; p. 76) argues that "the ability of people in an area to distinguish those present for legitimate purposes from potential offenders affects vulnerability" to crime. This perspective is endorsed by Felson (2006) who explains that the capability of a guardian is determined by his/her knowledge of what to look for during supervision. Thus, Felson (2006) implies that a fundamental requirement of a capable guardian is knowledge and information about their immediate surroundings and the context in which they find themselves. An essential prerequisite to the ability to distinguish potential offenders from benevolent others, therefore, is a basic awareness of the types of people, behavior and activity that is considered normal or typical of particular micro-places at different times. This awareness is likely to be enhanced through direct, consistent supervision over time, as it develops the capable guardian's ability to discern people or situations that stand out from the context in which they find themselves.

Although no research has been done to date on the informal guardian's ability to distinguish potential offenders from benevolent users of space, our understanding of this process may be enlightened by research that has explored how formal guardians, like police officers, develop this level of expertise. In their investigation into police decisionmaking and practice, Quinton et. al (2000) observed and interviewed over 100 police officers from the United Kingdom, asking them what it is about a person that attracts police attention. They found that police suspicion is aroused when they see an individual who stands out, or is perceived as being 'out of place'. One response team officer reported: "With experience of criminals [you] get an eye for what stands out" (Quinton et. al, 2000; p. 20). The study concludes that for formal guardians like the police, familiarity with context, i.e., knowledge of both the local resident and visiting populations, provides an important foundation for identifying suspiciousness. It would be interesting to examine the extent to which this principle extends to informal guardianship processes. 
Recent research from artificial intelligence corroborates this emphasis on detecting suspicious behavior based on cues that are out of the ordinary. Rowe (2005) came up with a metric for measuring the suspiciousness of people moving within a delimited space, based "on only periodic knowledge of their positions" (p. 1). He argues that this requires an assessment of the behavior, visibility and noticeability ${ }^{1}$ of the average individual moving within the space, compared to that of a particular individual. Suspicion is aroused if the behavior, visibility and conspicuousness of the particular individual is anomalous compared to that of the average individual. This type of sensory network is increasingly being used to monitor and detect suspicious behavior for United States homeland security (Rowe, 2005), and has major implications for research on guardianship, as it suggests that suspicious behavior is accompanied by some very specific, overtly detectable and predictable cues.

\section{The Criminal 'Appearance'}

There is also a wealth of literature from the field of psychology that addresses this issue about the ability to identify criminals, but in contrast to the previously mentioned perspectives, this research concludes that people distinguish offenders from others based on universally-held stereotypes that transcend context-specific information. Madriz (1997) argues that there are pervasive images of who is or is not criminal, and these images are based largely on stigma, labeling and biases about the physical appearance and behavior of criminals (Shoemaker \& South, 1978). Based on her interviews with women about their perception of offenders, Madriz (1997) reported that the most popular image of criminals is one of men who are poor, uneducated and come from minority groups. These studies raise the question of the extent to which these criminal stereotypes shape guardians' perceptions of who is and is not likely to be an offender.

\section{Beyond Availability: Guardianship \& the Willingness to Intervene}

\footnotetext{
${ }^{1}$ The cue category Behavior in this study refers to an agent's abrupt changes in path direction/speed, communication with other suspicious agents and a lack of goal-directed behavior. Visibility refers to the agent's attempt to avoid visibility through concealment. Noticeability refers to the agent's use of noticeable signals or loud noises.
} 
Once a capable guardian has a substantial level of familiarity with his/her context, and detects a potential offender or suspicious activity, the final test of capability is whether or not he/she chooses to intervene to prevent or disrupt a crime event. This brings us to another innate feature of capable guardianship that requires further exploration - the willingness to intervene when necessary.

Within the framework of social disorganization theory, Sampson et. al (1997) argued that the willingness to intervene goes hand in had with residents' social cohesion, and is aimed at maintaining shared standards of well-being within neighborhoods. Thus, Sampson et. al (1997) explain that the willingness to intervene on behalf of a common good reflects the collective efficacy of a neighborhood, and is linked to reduced incidence of violent crime.

Other research on bystander intervention into crime events comes from the field of social psychology, and suggests that the critical factors in the decision to intervene are individual rather than collective factors, such as the physical capability of the guardian (eg. size, height, gender) and his "training" (eg. life-saving, medical and self-defense training) (Huston et. al, 1981; p. 15). Huston et. al (1981) argue that these are the individual factors that determine how skilled and competent bystanders are as 'protectors', and consequently, how willing they are to intervene. When they compared a sample of 32 individuals who intervened in crime events to individuals who had not, Huston et. al (1981) reported that crime interveners differed markedly from noninterveners as they reported significantly greater exposure to criminal victimizationboth directly (being prior crime victims themselves) and indirectly (witnessing a crime).

Felson (2006) takes this perspective a step further, as he explains that, coupled with their knowledge of what to look for, the capability of a guardian is also determined by a basic understanding of what his/her role is in preventing crime. This suggests that a certain level of expertise and experience is required, not only for detecting potential offenders, but also for determining a guardian's willingness to intervene. It seems intuitive to surmise that the more experience and knowledge guardians have about their context, 
about crime and about self-protective behaviors, the more confident they will be about their capability, and the greater their willingness to intervene.

\section{The Current Study}

With this in mind, the aim of this paper is to take the next step forward in the research on guardianship by investigating which tools aid in transforming an available residential guardian into one who is capable of discouraging crime. Availability may be sufficient in certain circumstances to thwart the opportunity for certain types of crime, and thus, to prevent crime from occurring ${ }^{2}$. In other crime situations, available guardians may discourage planned criminal acts before they are actually executed, by monitoring events that stand out as being out of place or suspicious. Guardians may also be instrumental in determining whether a crime is merely attempted or actually completed, as they have the power to take action by intervening when they observe a crime in progress. In this way, it seems that a capable guardian may not only be able to prevent different types of crime, but may also function as a control agent at different stages of the crime event.

Although the vast majority of studies operationalise capable guardianship in terms of household occupancy or availability, this paper will build on the model of guardianship intensity by Reynald (2009) by focusing on the guardianship stages of monitoring and intervention in order to investigate what guardians look for during supervision, and what factors affect their decision about whether or not to intervene when they observe something suspicious. This paper will focus on residential guardians as the crime control agents who are most likely to assume primary responsibility (Felson, 1995) for their residential space, including the people and property contained therein. In this way, the current study will treat residential guardians as the aggregate group of crime controllers within the residential context, subsuming both handlers of potential offenders and place managers.

With this in mind, this study aims to answer the following research questions:

\footnotetext{
${ }^{2}$ Felson (1995) provides the example of a retired person at home whose presence may discourage daytime burglary of his property as well as neighboring properties.
} 
1) How do capable residential guardians distinguish between potential offenders and benevolent others?

a. What specific cues have aroused their suspicion during past instances of supervision?

b. To what extent does this ability distinguish capable guardians from potential guardians who are available?

2) What are some of the salient factors that affect a residential guardian's willingness to intervene when they observe suspicious activity in their immediate surroundings?

For the purposes of this study, we chose to interview available residential guardians themselves to find out how they make these types of guardianship decisions. This will be the first criminological study that targets available, residential guardians for in-depth, qualitative interviews in an attempt to uncover some of the underlying decision-making processes that affect capable guardianship at micro-places.

\section{Method}

\section{Study Setting}

Thirteen neighborhoods were selected from the Dutch province of South-Holland for this study. The Hague was chosen, along with the nearby village of Oud-Ade, because of its diversity, housing some of the wealthiest and some of the poorest neighborhoods in the Netherlands. The neighborhoods were selected for this study based on their variations in crime rate, income and non-native-population (see Appendix 1). This decision was taken in order to facilitate a comparison of how decisions taken by potential guardians may differ depending on the socio-economic context.

\section{Participant Sample}

Interviewers were dispatched to the respective neighborhoods where they went from house to house, ringing doorbells and knocking on doors, in order to solicit the participation of residents in the study. Interviewers initially sought to balance the sample 
of participants by including both residents and passers-by in their selection, but it turned out that the vast majority of passers-by that were approached were actually residents of the respective neighborhoods. Consequently, the final sample of participants was restricted to neighborhood residents who were at home or in their home neighborhoods during the daytime. Interviews were conducted during weekdays and weekends in April 2008, and lasted approximately 30 minutes. In the final sample of 255 participants, the average number of respondents across all neighborhoods was 20 , with $48 \%$ male participants and $52 \%$ female.

\section{Data Collection Procedure}

Once residents gave their consent to participate in the study, researchers conducted interviews in pairs, and used a hand-held tape recorder to record the interviews. The interviews were semi-structured, and participants were asked to draw on their past experiences with crime-related incidents on their street when answering our main interview questions:

1) Have you ever seen anything or anyone on your street that struck you as being suspicious?

1.1) What specific characteristics of the person or situation aroused your suspicion?

2) If you see something suspicious, what would you ordinarily do? Would you intervene yourself?

\section{Data Analysis Procedure}

Miles \& Huberman's (1994) Matrix Analysis was employed to analyze the data obtained from interviews with 255 participants. This methodology utilizes three core stages of data analysis: data reduction, data display and conclusion drawing/verification (see Appendix 2 for an illustration of how the data was reduced, Figure 5 for the data display, and the Conclusion Drawing/Verification section of results).

In order to validate some of the information obtained from the interviews, we compared resident responses with (i) the amount of property crime recorded by The Hague police (HKS) between 2004 and 2006, (ii) the average income per household inhabitant in 2004 
recorded by the Central Bureau of Statistics (CBS) in the Netherlands, and (iii) the percentage of households headed by non-Western immigrants in 2006 (CBS).

\section{Results}

At the heart of the concept of guardianship is the mechanism of supervision, which inherently implies regulation and control through surveillance. Built in to this control mechanism is the assumption that, through supervision, guardians are able to regulate what occurs in their space via their ability to distinguish potential threats to safety from benevolent users of space. As potential guardians, therefore, participants were asked two main questions. The first question was designed to elicit from respondents what features or characteristics guardians look out for during supervision that aid in distinguishing potential offenders from benevolent others:

\section{Q1): Have you ever seen anything or anyone on your street that struck you as being} suspicious?
Yes- $217(85 \%)$
No, I don't pay attention- $38(15 \%)$

\section{Contextual Awareness \& the Willingness to Monitor}

Most interesting was the fact that 15 per cent of respondents reported that they could not identify specific characteristics that would arouse their suspicion because they simply do not pay sufficient attention to what happens on their street:

P31: "I hardly ever see anything. I don't pay attention to what's happening outside my window."

P12: "I don't supervise. That's not my responsibility. I don't pay attention to these kinds of things at all."

P181: “I wouldn't know...It's very, very terrible, but I don't pay attention” P249: "I keep myself aloof and I experience nothing... I have no contact so then I wouldn't know..."

P107: "I have a child so I don't have the time always to pay attention to what other people are doing" 
Of further note is that fact that 68 per cent of these "oblivious" respondents reside in high crime neighborhoods in The Hague. Collectively, these responses speak to the theme willingness to monitor, as they commonly convey the following salient points:-

(i) this proportion of the sample are not in the habit of monitoring their surroundings,

(ii) they choose not to engage in supervision for several reasons (eg. they don't have the time, they don't view it as their responsibility, they don't want to get involved)

(iii) their unwillingness to monitor has an adverse effect on the knowledge they have about their residential space.

Thus, these responses provide evidence of two critical and inter-related points: the first is that monitoring is not an automatic process. Even when residents are available and have the physical capability of monitoring their space, they often choose not to engage in any form supervision. The willingness to monitor, therefore, reveals itself as a critical dimension of capable guardianship.

The second main issue is that the absence of monitoring has a direct effect on the level of awareness that residents have of their residential context. The lack of awareness, in turn, compromises residents' ability to act as capable guardians, as it seems to dull the ability to distinguish benevolent from malevolent users of space, and by extension, the level of control that residents have over their space.

These findings were validated by responses from other residents which provide evidence that the reverse also holds true: while the lack of monitoring has a negative effect on awareness, consistent monitoring actually reinforces awareness and knowledge about the residential environment, and, by extension, bolsters capable guardianship:

P62: "It has happened to me twice before that I observed people doing things that were suspicious here. But if you really want to know for a fact what is suspicious on this street, you must have lived here for some years. Then you will know exactly what to pay attention to. Then you see those who have bad intentions." 
P199:"Everyone and everything that lives here is suspicious. To recognize certain types, you must look outside. You must know at least a little. You should come here one evening, then you will see what I mean. If you live here, it is rather normal. But as an outsider, not."

P100: "If something happens... I write down descriptions. But all the neighbors here are very alert as well."

P131: "People are suspicious if I don't know them, if I can't place them."

Not only was there a noticeable difference in contextual awareness between participants who monitored and those who did not, but those who did engage in monitoring also highlighted some of the strategies they employ to monitor suspicious situations. One participant explained: "if I sit and watch from upstairs, they don't see me"(P38), while another reported: "I have a camera...that I use when I see suspicious people or incidents that are suspicious." (P210).

In addition to monitoring, contextual knowledge and awareness also seem to be enhanced by social networking within a residential environment. Some residents explained how their awareness of what was happening in their neighborhood came from information they received from interacting with neighbors:

P61:"... you hear so much talk about young people and so, then I am encouraged to keep an eye on them when I see them."

P98: "I go running with a neighbor, and she told me that another neighbor of ours who was threatened with a knife to their throat. Now I always run very fast, so if they threaten me, I can get away."

\section{Q1.1): What specific characteristics of the person or situation aroused your suspicion?}

As a result of their willingness to engage in regular monitoring and supervision of their surroundings, 85 per cent of participants were able to provide a list of cues that have, in the past, aroused their suspicion.

\section{Characteristics used to detect Potential Offenders}

They identified physical characteristics- such as the use of concealing clothing and groups of ethnic minorities- and behavioral characteristics, including aggressiveness and 
attempts at concealment, as features that aroused their suspicion. Most participants mentioned several characteristics that triggered their suspicion, but only those that were mentioned by more than 20 respondents were included in the analysis.

The characteristics that were mentioned most often were then analyzed and grouped together in conceptually clustered themes based on their shared meaning. Table 1 shows the five overarching categories that surfaced from participants' most frequent responses to question 1.1. (See Appendix 2 for a more detailed depiction of the data reduction process.)

\section{<Table 1 about here>}

\section{The Criminal Appearance Myth?}

Although many participants identified some physical characteristics that they associate with criminality in their neighborhoods- such as groups of young boys, ethnic minorities and unkept clothing- these characteristics were often mentioned as constituents of a more broadly-defined behavioral profile that varies in different neighborhood contexts, rather than features that are independently sufficient to distinguish potential offenders from others.

In fact, physical characteristics such as these were often mentioned as a means of identifying individuals who stood out as being out of place or foreign to the neighborhood context. In this way, participants explained that the criterion for identifying potential offenders is context-specific:

P40: "Unrecognizable people who do not fit in the neighborhood...that makes me alert." P59: "I know all the people who live here, so if I see someone hanging around who I don't know, I get suspicious."

P46: "I don't pay attention to specific physical characteristics or behavior characteristics, but I know when I see something out of the ordinary or strange." P52: "What strikes me as suspicious depends on the context. If you see a neat looking, well dressed man here, it is not strange. But someone whose appearance looks unattended is notable. So are immigrants." 
Having clarified the most significant cues they use to detect potential offenders in their residential space, guardians were then asked the second main research question:

\section{Q2): If you see something suspicious, what would you ordinarily do? Would you intervene yourself?}

Participants explained how they would respond upon observing something suspicious, and in doing so, exposed 5 overarching categories of respondents:

(i) Residents who turn a blind eye to crime-related events in progress

(ii) Residents who are only willing to monitor covertly

(iii)Residents willing to intervene indirectly

(iv)Residents willing to intervene directly

(v) Residents willing to intervene both directly and indirectly

<Table 2 about here>

\section{The Non-Interveners}

Of the 217 respondents who admitted to supervising their residential space, 9 per cent reported that when they see something suspicious, they choose to ignore it because they don't want to get involved (see Table 2):

P45: "I would not intervene even if I see something happening..."

P79: "If something happens, I think it would be beyond me to do anything to intervene." P89: “I would not take any action myself. I wouldn't call the police either. I won't do anything." P173: "I do not react or interfere myself. My experience is that it does not always help. So I keep my distance or ignore it."

P202: "I don't do anything. I don't want to be involved."

Table 2 also shows that $11 \%$ of residents indicated that while they still would not take any direct or indirect measures to intervene in the suspicious event, they would keep monitoring so they are aware of how the event develops:

P176: "I take no action. I simply stay alert." 
P177: "I keep watching, but I don't get involved."

P184: "I become more alert and watch to see what they do so I can identify them."

Taken together, these results may be interpreted to indicate that 20 per cent of residents in the sub-sample reported that they are unwilling to take any action to intervene in a crime-related event in progress.

\section{The Interveners}

80 per cent of residents reported that they would take some action to intervene if they observed crime or related activities. Table 2 shows that 41 per cent indicated that they prefer to intervene indirectly by notifying the police or other authorities: P59: "My husband regularly calls the police if something happens here on the street. This helps keep order and neatness on the street."

P255: "I sometimes react. First I monitor them, and if they do something threatening, I would call the police if necessary. But I would not take it upon myself to do something."

P64: "Intervene? You think I'm crazy? I would call the police if there is something wrong."

P66: "I will not take action myself to prevent someone else from being victimized. Only if I myself am a victim of a robbery. I would rather call the police."

P230: “I would do nothing myself. I would call the police. I am really not a hero.”

16 per cent reported that they would personally and deliberately take action to disrupt or prevent crime-related events from occurring, by either communicating with suspicious parties directly or physically intervening in a crime in progress:

P5: "I physically get involved when I see something about to happen."

P50: "If I see something [suspicious] like this, I would certainly call out to the person and ask what they're doing, let them know I see what they're doing. "

P62: "I was running through the park one day and I saw someone standing suspiciously at a car, and I knew immediately what his plan was. He looked at me and stopped what he was doing, clearly waiting till I was gone. But I confronted him. There was also an incident that I observed in progress at the school and I shouted out to the offenders: 'I can see what you're up to'. Just then, an old school teacher came on the scene and they ran off."

P162: "I do not call the police. I have no need for the police. I will take the responsibility myself." 
23 per cent explained that while they would certainly take some form of action to intervene, their choice of direct or indirect intervention would depend on the seriousness of the incident being observed (see Table 2):

P72: "If I see minor incidents, like if I see someone trying to steal small, cheap goods, then I would intervene. But if I see someone climbing into someone's house, then I would call the police"

P223: "I will call the police for something major. But for things like disorder, I can deal with that myself."

P81: "To intervene or not presents a dilemma. It depends on the situation. If it is something minor, I will intervene myself. However, if it is something more serious, I will... call the police."

P138: "I would first say something myself; address the situation myself. If that doesn't work, then I would call the police."

This category of responses is most interesting, as it suggests that in certain types of crime situations, there may well be a limit to the capability of even an active guardian in preventing or thwarting a crime event. Clearly, even active, capable guardians are aware that their direct intervention may not be sufficient to discourage certain types of offenders that engage in crimes that are more serious in nature. This directs our attention to the fact that, for certain types of crime, and at a certain stage of the crime event itself, it is possible that the situation may escalate beyond the control of even an active, capable guardian, in which case they are forced to rely on the authorities for assistance.

\section{Neighborhood Context, the Willingness to Supervise and the Decision to Intervene}

The data obtained from residents highlights the fact that the residential context cannot be overlooked as one of the principal factors involved in determining the willingness to supervise and the willingness to intervene. In order to briefly explore the validity of this relationship, we compared residents' reports about their supervision and intervention practices with three categories of neighborhood characteristics:- (i) the amount of property crime recorded by The Hague police (HKS) between 2004 and 2006, (ii) the average income per household inhabitant in 2004 (CBS-Central Bureau of Statistics), and (iii) the percentage of households headed by non-Western immigrants in 2006 (CBS).

<Figure 1 about here> 


\section{Crime, Supervision \& Intervention}

Figure 1 shows that in the high crime neighborhoods, the percentage of residents who are unwilling to supervise is double that of the low crime neighborhoods. When we examine the types of intervention residents opt for, Figure 1 shows that the low crime neighborhoods have more residents who are willing to intervene directly and indirectly than the high crime neighborhoods.

\section{<Figure 2 about here>}

\section{Income, Supervision \& Intervention}

Similar patterns are revealed even when we compare supervision and intervention practices in neighborhoods with varying income levels. Figure 2 shows that the percentage of residents who were reportedly unwilling to supervise their surroundings is highest in the low income neighborhoods. This percentage decreases in the middle income group and is lowest in the high income group. When we examine the types of intervention reported, Figure 2 shows that more residents in the middle and high income groups are reportedly willing to intervene indirectly, with the highest number of reported direct interveners coming from the middle income neighborhoods.

\section{$<$ Figure 3 about here>}

\section{Ethnic Composition, Supervision \& Intervention}

Figure 4 shows that neighborhoods with the highest number of non-western immigrants also had the highest percentage of residents who were unwilling to supervise their residential space. Indirect intervention was highest in neighborhoods with the lowest number of ethnic minorities, while direct intervention was lowest in neighborhoods with the highest number of ethnic minorities (see Figure 3). 
As a whole, therefore, these results suggest that residential context does indeed play an important role, both in residents' reported supervision and intervention practices. In neighborhoods that tend to have comparatively lower crime, higher income and lower numbers of ethnic minorities, the willingness to supervise and the willingness to intervene directly is considerably higher than in others.

\section{Interveners vs. Non-Interveners:}

\section{Factors affecting the Willingness to Supervise \& the Decision to Intervene}

In their discussion of the various reactions they would have to suspicious incidents, participants made reference to some of the factors that affect their decision to intervene in a crime or related event. Six salient factors were extrapolated from participant responses:

\section{1) Sense of obligation/responsibility}

Participants who reported that they are willing to supervise and intervene directly explained that one of their motivations for doing so is the sense of responsibility they feel for protecting those who come under threat in their immediate surroundings:

P166: "I feel obligated to do something, take some action to help if I can."

P28: 'I don't want it on my conscience that my neighbors are dead suddenly because I didn't help."

P125: 'It's a social neighborhood. You know everyone and therefore you have a big responsibility to keep an eye."

Conversely, those who reported unwillingness to supervise or intervene explained that it is not their responsibility to protect others:

P41: “.I am not an agent of the law myself. If I was, I would do something. But I am only a citizen."

P12: 'I don't supervise. That's not my responsibility. I don't pay attention to these kinds of things at all."

P251: "I react to anti-social behavior, like shouting, if it is directed at me or my girlfriend, but if it is directed to someone else, then it is not my business."

\section{2) Perception of residential environment}


The 'sense of responsibility' that residents feel for protecting their space and its users is directly linked to residents' perceptions of their residential environment. These perceptions may, in turn, be determined to some extent by the neighborhood contextual factors mentioned in the previous section. In fact, many residents explained the ways in which their perceptions of their residential environments have a direct effect on their willingness to supervise and intervene when necessary.

In Transvaalkwartier for example, (a neighborhood with comparatively high crime, low income and a high percentage of foreigners), two residents from the same street reported: P39:"People on this street in general will not get involved themselves. But if I see something, I will say something or do whatever I can do myself to stop it, and I will always call the police." P43:"I would say something if I see them [groups of young boys] doing something suspicious, but nobody here will help you. Everyone is for himself."

In Schilderswijk-West, a neighborhood that falls into the same socio-economic categories, residents explained:

P210: "I don't call the police [if I see something suspicious]. If you ring the neighborhood officer, then he comes hours later. Occasionally, you see a police car racing through the streets, but they don't take the time to stop by or so...More cameras and more [police] supervision are needed badly in this neighborhood."

P211: "There is a lot of brutal behavior here. The street is completely dirty. I will not get involved in anything myself here."

In contrast, residents from the low-crime village of Oud-Ade explained:

P135: "Firstly, I will keep an eye [if I see something suspicious]. If it is something serious, I will call the police...but this rarely happens here...it is a safe village. There is only one entrance and exit."

P129: "I regularly look out of my window at night when I can't sleep... and I have never seen much happening there... everyone here knows each other."

\section{3) Training}

Similarly, many participants who indicated that they supervise regularly and intervene directly when necessary, mentioned prior training that they believe enhances their knowledge and instincts when it comes to identifying potential offenders and taking action to deter them: 
P162: "My whole life I have been involved in personal security (bodyguarding etc.) and as a result of that I have been trained what to look for...like nervousness."

P244: "I do a lot of security work, so I can spot pickpockets."

P26: "If I see something suspicious, I keep monitoring the situation. I work with the police force myself, so I recognize offenders easily."

P180: "That comes especially from my job at the police force. You see it immediately when something is suspicious."

P188: "You can easily recognize an offender. I work as a security guard for a jewelry store, so I come into enough contact with them."

\section{4) Risk to Personal Safety}

Both interveners and non-interveners repeatedly mentioned that their assessment of the risk to their own personal safety was a major consideration in their decision to intervene. Based on the trend of these responses, it seemed that the more likely they believed their safety to be compromised during intervention, the less likely they would take direct action to thwart a criminal event:

P159: "If I don't think I will put myself in danger by getting involved, I will do so."

P120: "I have gotten involved before, but only when I am fairly certain I will not be harmed myself."

P82: "I am not certain whether I would intervene or not. It depends on my own safety."

P167: “As long as they cannot harm me, I will say something myself, like 'get some education from your parents'. If something really serious happens, I will call the police."

P68: "I find it too dangerous to physically intervene myself."

\section{5) Availability of tools for protection}

The idea of preserving their own personal safety was also reflected in participants' explanation that they are more willing to intervene when they have tools for protection at their disposal:

P20: "I take a walking stick with me wherever I go, whenever I step out of my front door, for protection."

P33: "If I have my dogs with me, I will intervene myself if I see something happening." P63: "If someone is alone, I will take action myself, because we also have a dog which deters people a lot..."

\section{6) Physical Competence}


Both interveners and non-interveners were also concerned about their physical competence when it came to obstructing crime events. Some explained that factors like age and stature were critical in their decision about whether or not to intervene directly:

P45: "I would not intervene even if I see something happening because I am too old for that."

P184: "It has been discussed and I have a neighbor man who I can call if I see something suspicious. But I have frequently also rung the police." (age 75)

P253: "I keep looking at them [suspicious people] and see how to proceed further. Someone

bigger makes a more threatening impression."

\section{Conclusion Drawing/Verification}

The salient factors outlined in the preceding section help influence various stages of decision-making by guardians, and ultimately, help an available guardian develop into one who is capable of discouraging a variety of crime opportunities. When the results of this study are drawn together, therefore, the distinct stages of decision-making culminate to determine the extent of an available guardian's capability (see Figure 4).

Once a guardian is at home and available, Figure 4 shows that the first stage of the guardian's decision-making process involves whether or not to engage in the monitoring of residential space. We can observe in Figure 4 that the decision to monitor is influenced both by the sense of responsibility residents feel towards their residential community, as well as their overall perception of their residential context. If an available guardian chooses not to monitor, this inevitably has a negative effect on his capability, since this choice immediately renders him incapable of disrupting some (though not all) opportunities for crime ${ }^{3}$. Likewise, if an available guardian does choose to monitor, this boosts his capability.

The second stage of the guardian's decision making process, therefore, is dependent on monitoring. This stage involves the ability, during monitoring, to detect suspicious, crime-related activity. Available guardians' ability to do this is determined by (i) the extent to which they are familiar with their residential context and therefore able to

\footnotetext{
${ }^{3}$ A burglar, for instance, may be deterred from offending at a particular property if it is occupied, but if the guardian who is available there does not monitor, he is incapable of preventing the burglar from targeting another house on that street which may be unoccupied.
} 
distinguish people or events that are out of the ordinary, and by (ii) prior training they may have had in detecting suspicious acts or situations (see Figure 4). Again at this stage, an available guardian's ability to detect suspiciousness boosts his capability.

If suspicious activity is observed, this brings us to the ultimate stage of a guardian's decision-making- whether or not to intervene. Figure 5 shows that the choice to intervene and the type of intervention taken is affected by the sense of responsibility the guardian feels towards his residential community, his physical competence to intervene in the crime or related event, the availability of tools for his own protection, and the severity of the incident observed. Even though the choice not to intervene may still allow for the maintenance of covert monitoring, it, nevertheless, has a negative effect on capability, since the decision to either ignore the event or covertly keep watching both have the same ineffective outcome. Neither course of action contributes to the disruption of the crime event.

If residents do choose to intervene, either directly or indirectly depending on the risk to their own personal safety, this decision again boosts their capability since it increases the chances of disrupting the crime event in progress. Direct intervention has the potential to boost capability even moreso than indirect intervention, since the active response is immediate when intervention is direct, but is likely to be delayed for indirect intervention. The likelihood of disrupting the crime event, therefore, is higher with a direct, active response.

\section{<Figure 4 about here>}

\section{Summary of Results}

The results of this study aid in providing the capable guardian's profile of potential offenders, as it provides information about what cues capable guardians use to detect potential offenders from benevolent users of space. Based on responses from household residents, the first cue that arouses suspicion is an individual who doesn't belong or stands out from the context in which he is being observed. Resident responses suggest 
that guardians pay closer attention to the behavior of a suspect than physical appearance alone when judging whether he/she is a potential threat to safety.

Capable guardians explained that there are five observable behavioral categories that distinguish individuals who are seeking opportunities for crime from benevolent others:

(1) anti-social behavior (eg. aggressiveness, acts of intimidation, shouting etc.)

(2) secretive behavior (attempts at hiding, concealment)

(3) aimlessness (walking around with no apparent aim or purpose)

(4) nervous response to monitoring

(5) eyeing potential targets (looking into property windows, at cars etc.)

Further to this, the results of this study also aid in clarifying the significant factors that determine the decisions to supervise and to intervene, the most fundamental of which seem to be neighborhood contextual factors. Results show that there are common factors that affect both decisions, including internal factors: such as perceptions of the residential context and the personal sense of responsibility for the residential space; as well as external factors: such as familiarity with context and prior training. These factors converge in the guardian's assessment of the severity of the incident, and an assessment of the risks to his personal safety. Depending on their assessment of these risks, a guardian decides not to intervene at all, to intervene indirectly by calling the police (if the risks to his safety are too great) or to intervene directly by physically getting involved. Both direct and indirect intervention can be seen as action taken on the part of the guardian to either prevent a crime from occurring or to thwart a crime event in progress.

Overall, the results of this study illuminate some of the salient stages of a guardians' decision-making, and illustrate how the decisions taken at these different stages determine how capable a guardian is of preventing crime in his residential space.

\section{Discussion/Conclusion}

The results of this study reveal some of the critical decision-making processes involved in guardianship.

This study was aimed at answering the following research questions: 
1) How do capable guardians distinguish between potential offenders and benevolent others?

a. What specific cues have aroused their suspicion during past instances of supervision?

b. To what extent does this ability distinguish capable guardians from potential guardians who are available?

2) What are some of the salient factors that affect a guardian's willingness to intervene when they observe suspicious activity in their immediate surroundings?

\section{Monitoring: A Pivotal Dimension of Capable Guardianship}

Results from this study reinforce Reynald's (2009) model of guardianship intensity, as they show, in the first instance, that the capability of a guardian is not only determined by his availability. The results of this study confirm that while availability is a fundamental component of a guardian's capability, the extent of a guardian's capability is critically determined by his willingness to monitor. Thus, while availability of a guardian is the first critical stage of guardianship intensity, it is not representative of how capable that guardian will be of preventing crime. Availability alone, therefore, is not a sufficient indicator of the intensity of capable guardianship at place.

Accordingly, this study confirms that actual monitoring is a prerequisite for capable guardianship, as it affects a guardian's contextual awareness, and by extension, his ability to distinguish potential offenders from benevolent users of space. Much of the guardianship research assumes that an available guardian is one who automatically supervises his surroundings, but the results of this study indicate that only when available guardians engage in the monitoring of surroundings are they capable of preventing crime. Monitoring guardians also reinforce their own capability by acquiring contextual knowledge and information through the act of monitoring itself. In this way, the evidence suggests that the mechanism of guardianship functions within a spectrum of capability, with availability, monitoring and intervention representing its continuous components. 
Contextual knowledge accumulated via consistent monitoring over time has surfaced as the cornerstone of decision-making involved in capable guardianship. Roncek (1981) explained that one of the innate judgments involved in reducing vulnerability to crime at place is the ability to distinguish potential offenders from benevolent others. The results of this study, therefore, confirm Felson's (2006) theory that contextual familiarity and knowledge is a fundamental precondition for capable guardianship, as it enhances the ability to discern individuals who are at a place for illegitimate purposes.

\section{Capable Guardians: Potential Offender Profile}

Like police officers, residential guardians seem to develop what may be described as a level of expertise when it comes to their ability to judge potential offenders from benevolent users of space. Similar to their formal counterparts in the Quinton et. al (2000) study, residential guardians' suspicion is initially aroused by people who seem out of place or stand out from the established context. Thus, only the guardians in the sample who engaged in consistent monitoring were able to provide interviewers with the specific cues they use to detect potential offenders. These capable guardians were able to provide 5 cue categories that most frequently draw their attention to illegitimate users of space. Consistent with Rowe's (2005) artificial-intelligence-based metric for suspiciousness, capable guardians reported that anti-social behavior (shouting, aggressiveness, intimidation etc.), secretive behavior (hiding, attempts at concealment) and aimlessness (hanging around with no goal or purpose) helped them identify individuals possibly present for illegitimate purposes. Additionally they explained that a nervous response to monitoring and eyeing potential targets were behavior patterns that often distinguish potential offenders from others.

Interestingly, structural cues alone highlighted by Madriz (1997) and Shoemaker \& South (1978)- such as clothing, physical appearance and ethnicity-were mentioned least often by participants as independent cues that help them determine who is and is not a potential offender. This suggests that, contrary to the conclusions espoused in the Madriz (1997) study, context-specific behavioral information is more influential than physical stereotypes in judging who is likely to be a potential offender. 
The Decision to Intervene when necessary: Types of Intervention

Results showed that when a potential offender is observed in the course of what appears to be suspicious or illegitimate activity, most monitoring guardians are willing to take some form of action to disrupt the crime event. The majority of guardians opt for indirect intervention, by calling the police or other authorities. This course of action is preferred, particularly for crime events that appear to be serious. For minor incidents, such as antisocial behavior or attempted property theft or break-ins, guardians are more willing to intervene directly by raising an alert or getting physically involved. A few guardians indicated that they would willingly intervene directly regardless of situational factors. This sub-group consisted of guardians who had some prior form of self-protective or security training, and/or prior experiences as witnesses or victims of crime. These results are consistent with Huston et. al's (1981) findings on motivations for bystander intervention, and Felson's (2006) perspective that a guardian's capability is determined, in part, by his understanding of his role in preventing crime.

These results suggest that the average capable guardian is willing to intervene once his/her personal safety is unlikely to be compromised. In reference to past experiences where they did intervene, many participants mentioned shouting at offenders they observed attempting to break in to a property, or attempting theft. Others mentioned having to confront groups of youth regarding anti-social behavior. Many also mentioned incidents where they were forced to call the police after initial attempts at intervention had no effect in deterring potential offenders. Taken together, these results indicate that capable guardians may be most useful in (i) preventing crime before it happens-i.e., controlling anti-social behavior and incivilities before they develop into serious crime incidents- and (ii) in the early, preparatory stages of the crime event-i.e., when offenders are preparing to commit their crimes or breach their targets, by looking into property windows, or checking to see if doors and windows are locked.

These results also raise the issue of self-protection versus the protection of others within the spectrum of guardianship. Many residents explained that they were more willing to 
intervene if their property or family were under threat, as compared to neighbors or other benevolent users of their residential space, lending support to Felson's (1995) classification of personal responsibility exercised by guardians over their own property, family or friends. These results also inevitably tie back into the role that the neighborhood context plays, both in the willingness to supervise and the willingness to intervene. The results of this study show that residents in neighborhoods characterized by comparatively low crime, high income and fewer ethnic minorities expressed a greater willingness to supervise and intervene when necessary. In contrast to the other groups, some residents from these neighborhoods explained that they possessed a good knowledge of the people in their area, and often described themselves as being sociable with each other, lending support for Sampson et. al's (1997) conclusions. These results suggest the importance of both individual and collective factors in determining a guardian's capability and willingness to prevent crime. The processes through which an individual's guardianship practices translates into a collective level of guardianship intensity within micro-contexts (eg. at the street level) and the macro (neighborhood) context remains a fruitful angle for further exploration.

Furthermore, the results indicate that, certainly within the residential context, residential guardians may function simultaneously as guardians over targets (both their own as well as those belonging to neighbors), as handlers of potential offenders (eg., in this study, over groups of young boys who cause a nuisance), as well as managers of places (their wider residential space). In this way, this study suggests that in certain contexts, such as the residential context, the roles of guardians, handlers and managers may not necessarily be distinct.

One of the inherent weaknesses of this study, however, is its reliance on self-report data from available guardians. Future research in this vein may benefit from systematic attempts at triangulation using secondary data sources. Another limitation of the current study revolves around the issue of the generalizability of these results. While the model of decision-making by guardians and the profile for the identification of potential offenders provide a valuable foundation for comparison for future research, these 
findings are limited in the extent to which they can be generalized to apply to guardians who are not available during the daytime, or to random samples in general. Furthermore, it may well be argued that the terminology used in our interview questions (for example, words like "suspicious") is vague at best. Research that takes this exploratory study forward may benefit from the use of better defined and more focused questioning.

In summary, the results of this study aid in illuminating the dimensions that make a guardian capable of preventing crime. In the first instance, the results reveal the utility of interviewing available guardians as a means of developing the theory and conceptualization of guardianship. They suggest that a capable guardian is set apart by his/her willingness to take action to prevent or discourage the occurrence of crime. The more action a guardian is willing to take-i.e., the more he monitors his surroundings and intervenes when he observes illegitimate activities- the higher the intensity of guardianship at a place. Monitoring builds contextual knowledge and awareness, and this enhances intuition about who is and is not suspicious. This, in turn, bolsters the confidence needed to actively prevent crime events from occurring. Thus, capable guardianship ultimately serves to fortify the sphere of control that residents have over their space.

\section{References}

Cohen, Lawrence E. \& Marcus Felson. 1979. "Social Change and Crime Rate Trends: A Routine Activity Approach.” American Sociological Review 44 (4):588-608.

Coupe, Timothy and Laurence Blake. 2006. "Daylight and Darkness Targeting Strategies and the Risks of being seen at Residential Burglaries." Criminology 44 (2):431-464.

Eck, John E. (1994). Drug Markets and Drug Places: A Case-Control Study of the Spatial Structure of Illicit Drug Dealing. Unpublished Ph.D. dissertation, University of Maryland, College Park. 
Felson, Marcus. 1995. "Those Who Discourage Crime." In Crime and Place: Crime Prevention Studies, Vol. 4, edited by J.E. Eck \& D. Weisburd. Monsey, NY: Criminal Justice Press.

Felson, Marcus. 2006. Crime and Nature. Thousand Oaks, CA: Sage.

Garofalo, James. \& David Clark. 1992. "Guardianship and Residential Burglary.” Justice Quarterly 9 (3):443-463.

Huston, Ted L., Mary Ruggerio, Ross Conner and Gilbert Geis. (1981). "Bystander Intervention into Crime: A Study Based on Naturally-Occurring Episodes." Social Psychology Quarterly 44 (1):14-23.

Madriz, Esther I. 1997. "Images of Criminals and Victims: A Study on Women's Fear and Social Control." Gender and Society 11 (3):342-356.

Miethe, Terance D., Mark C. Stafford and J. Scott Long. 1987. "Social differentiation in criminal victimization: A Test of Routine Activities/Lifestyle Theories." American Sociological Review 52 (2):184-194.

Miethe, Terance D. and Robert F. Meier 1990. "Criminal opportunity and victimization rates: A structural choice theory of criminal victimization." Journal of Research in Crime and Delinquency 27:243-266

Miethe, Terance D. and David McDowall. 1993. "Contextual Effects in Models of Criminal Victimization." Social Forces 71 (3):741-759.

Miles, Matthew B. and A. Michael Huberman. (1994). Qualitative Data Analysis: An Expanded Sourcebook. Thousand Oaks, CA: Sage.

Quinton, Paul, Nick Bland and Joel Miller. 2000. "Police stops, Decision-making and Practice." Police Research Series, Paper No. 130. London: Home Office. 
Reynald, Danielle M. (2009). “Guardianship in Action: Developing a new tool for measurement." Crime Prevention \& Community Safety: An International Journal, 11(1), $1-20$.

Roncek, Dennis W. 1981. "Dangerous Places: Crime and Residential Environment." Social Forces 60 (1):74-96.

Rowe, Neil C. 2005. "Detecting Suspicious Behavior from Positional Information." International Joint Conference on Artificial Intelligence, Edinburgh, United Kingdom. July, 2005.

Sampson, Robert J., Stephen W. Raudenbush and Felton Earls. 1997. "Neighbourhoods and Violent Crime: A Multilevel Study of Collective Efficacy." Science 277 (5328): 918-924.

Shoemaker, Donald J. and Donald R. South. 1978. "Nonverbal Images of Criminality and Deviance: Existence and Consequence." Criminal Justice Review 3:6580.

Wilcox, Pamela, Tamara D. Madensen and Marie Skubak Tillyer. 2007. "Guardianship in Context: Implications for Burglary Victimization Risk \& Prevention." Criminology 45 (4):771-803.

Wilcox Rountree, Pamela, Kenneth C. Land and Terance D. Miethe. 1994. "Macro-Micro Integration in the Study of Victimization: A Hierarchical Logistic Model Analysis across Seattle Neighborhoods. Criminology 32 (3):387-414. 


\section{Appendix 1: Characteristics of Neighborhoods Sample}

\begin{tabular}{|l|c|c|c|c|c|c|c|c|}
\hline \multicolumn{1}{|c|}{ Neighborhood } & \multicolumn{2}{c|}{$\begin{array}{c}\text { Property Crime } \\
\text { 2004-2006 }\end{array}$} & \multicolumn{2}{c|}{ Income Status } & \multicolumn{3}{c|}{ \% Foreign } \\
Inhabitants
\end{tabular}

*N/A is reported for those neighborhoods from which the relevant data was not available from official sources.

\section{Table 1: Frequency table based on reporting of cues that arouse criminal suspicion}

\begin{tabular}{|c|c|}
\hline Criminal Cues & $\begin{array}{c}\text { Frequency of cue } \\
\text { reporting }\end{array}$ \\
\hline $\begin{array}{c}\text { Anti-Social Behavior (drugs \& alcohol use on the street; } \\
\text { aggressive \& intimidating behavior; shouting etc.) }\end{array}$ & $98(47 \%)$ \\
\hline $\begin{array}{c}\text { Secretive Behavior (hiding, sneaking, attempts to conceal } \\
\text { appearance etc.) }\end{array}$ & $78(37 \%)$ \\
\hline Aimlessness (hanging around with no apparent purpose) & $47(18 \%)$ \\
\hline Nervous Response to Monitoring & $25(12 \%)$ \\
\hline $\begin{array}{c}\text { Eyeing potential targets (looking into property windows; } \\
\text { testing car doors to see if they're open; looking into cars } \\
\text { and at bicycles etc.) }\end{array}$ & $23(11 \%)$ \\
\hline \hline Total & $293(100 \%)$ \\
\hline \hline
\end{tabular}

*Based on responses to the question: Have you ever seen anything or anyone on your street that struck you as being suspicious? What specific characteristics of the person or situation aroused your suspicion? 
Table 2: Frequency table based on reporting of cues that arouse criminal suspicion

\begin{tabular}{|c|c|c|c|c|c|c|c|}
\hline $\begin{array}{c}\text { Neighborhood } \\
\text { Classification }\end{array}$ & $\begin{array}{c}\text { Turn a } \\
\text { blind eye }\end{array}$ & $\begin{array}{c}\text { Covert } \\
\text { Monitoring }\end{array}$ & $\begin{array}{c}\text { Total } \\
\text { Non- } \\
\text { Interveners }\end{array}$ & $\begin{array}{c}\text { Indirect } \\
\text { Intervention }\end{array}$ & $\begin{array}{c}\text { Direct } \\
\text { Intervention }\end{array}$ & $\begin{array}{c}\text { Both Direct } \\
\text { \& Indirect }\end{array}$ & $\begin{array}{c}\text { Total } \\
\text { Interveners }\end{array}$ \\
\hline $\begin{array}{c}\text { High Crime } \\
\text { Neighborhoods } \\
(\mathrm{n}=103)\end{array}$ & $19(9 \%)$ & $\begin{array}{c}10 \\
(5 \%)\end{array}$ & $\begin{array}{c}\mathbf{2 9} \\
(\mathbf{1 3 \%})\end{array}$ & $\begin{array}{c}32 \\
(15 \%)\end{array}$ & $\begin{array}{c}12 \\
(5 \%)\end{array}$ & $\begin{array}{c}30 \\
(14 \%)\end{array}$ & $\mathbf{7 4}$ \\
\hline $\begin{array}{c}\text { Low Crime } \\
\text { Neighborhoods } \\
(\mathrm{n}=114)\end{array}$ & 0 & 14 & $\mathbf{1 4}$ & 58 & 22 & 20 & $\mathbf{1 0 0}$ \\
\hline $\begin{array}{c}\text { Total } \\
(\mathrm{n}=217)\end{array}$ & $(0 \%)$ & $(6 \%)$ & $\mathbf{( 7 \% )}$ & $(27 \%)$ & $(10 \%)$ & $(9 \%)$ & $\mathbf{( 4 6 \% )}$ \\
\hline
\end{tabular}

*Based on responses to the question: If you see something suspicious, what would you ordinarily do? Would you intervene yourself?

Figure 1: Comparing Supervision \& Intervention with Crime

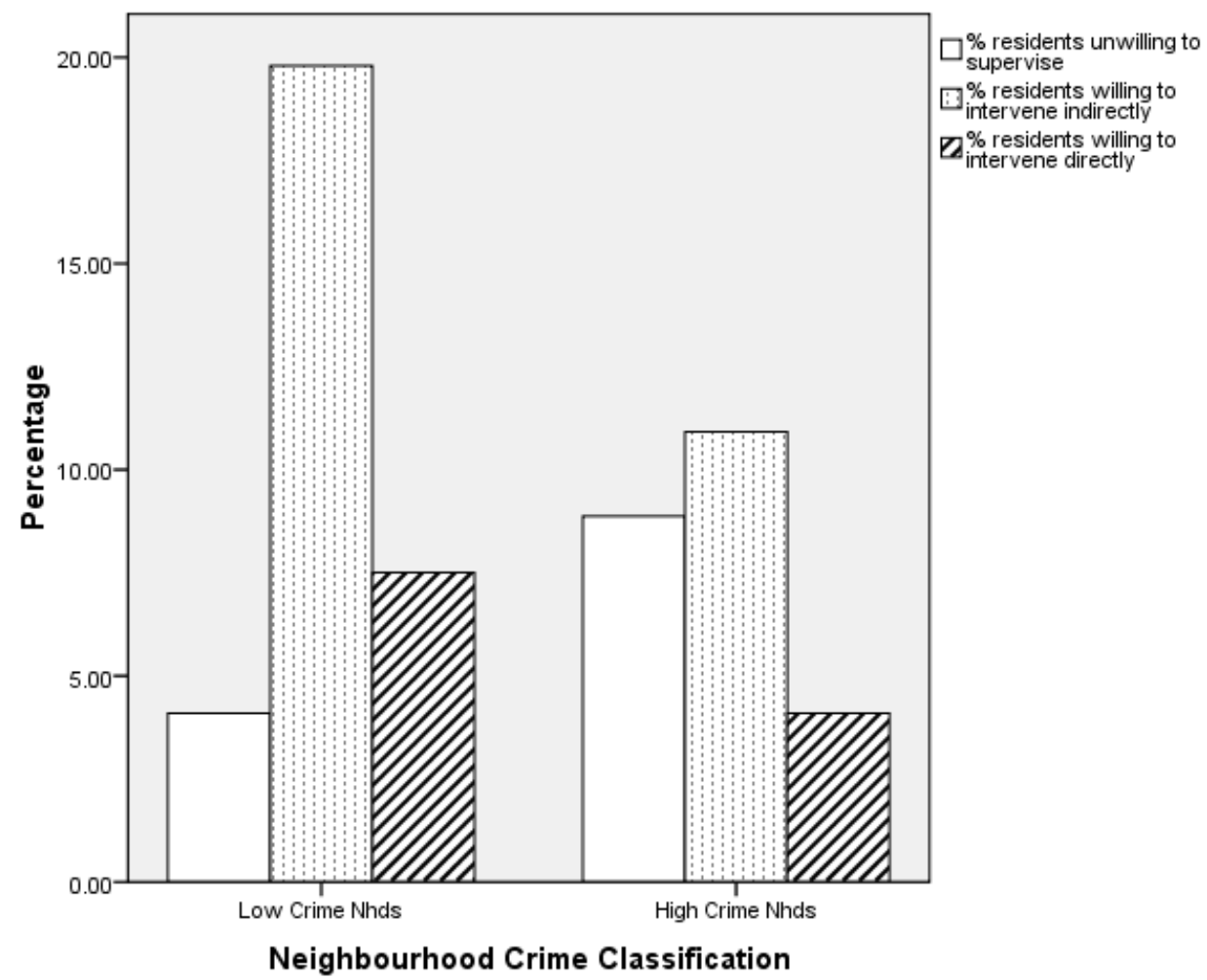


Figure 2: Comparing Supervision \& Intervention with Income

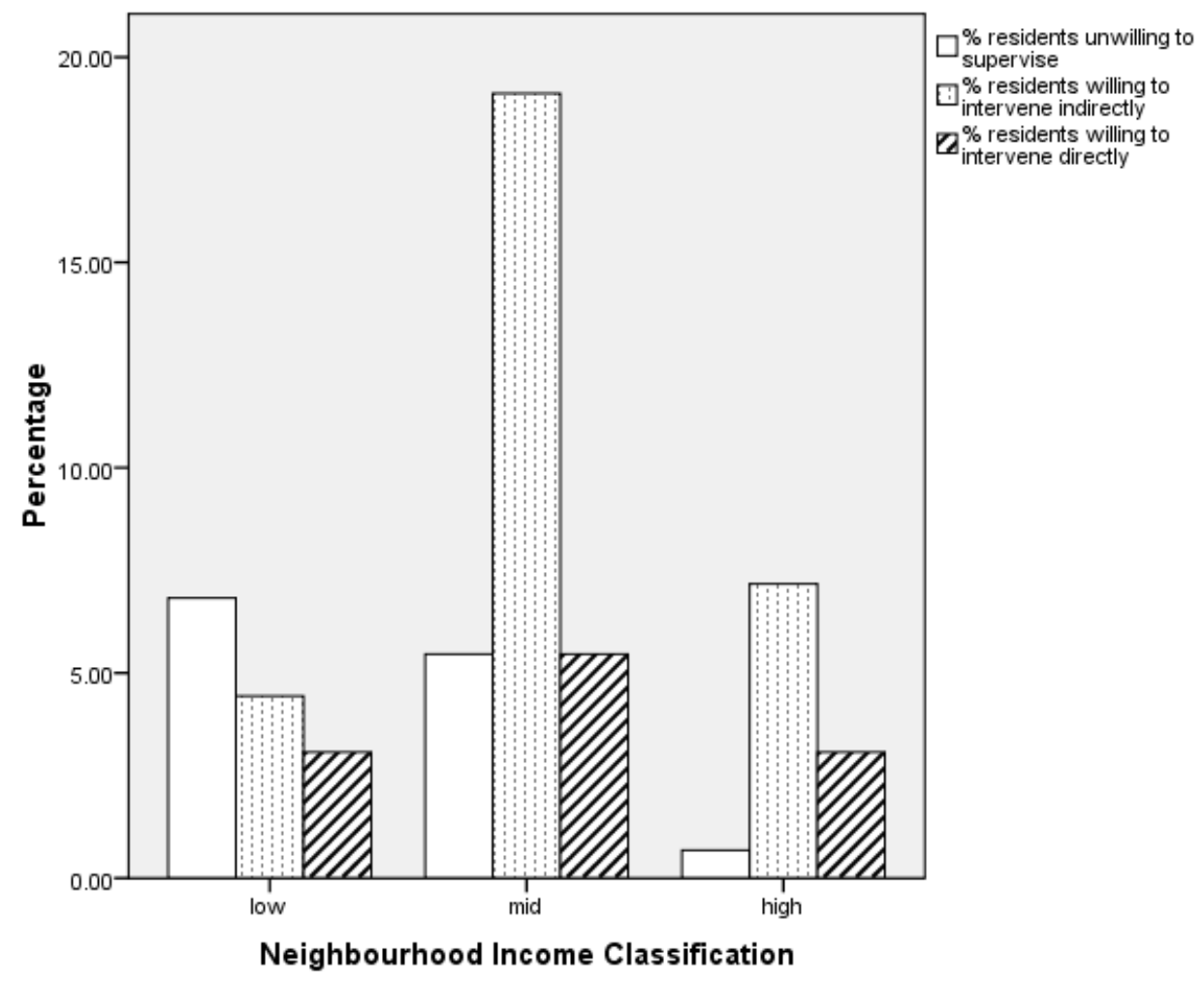

Figure 3: Comparing Supervision \& Intervention with Ethnic Composition

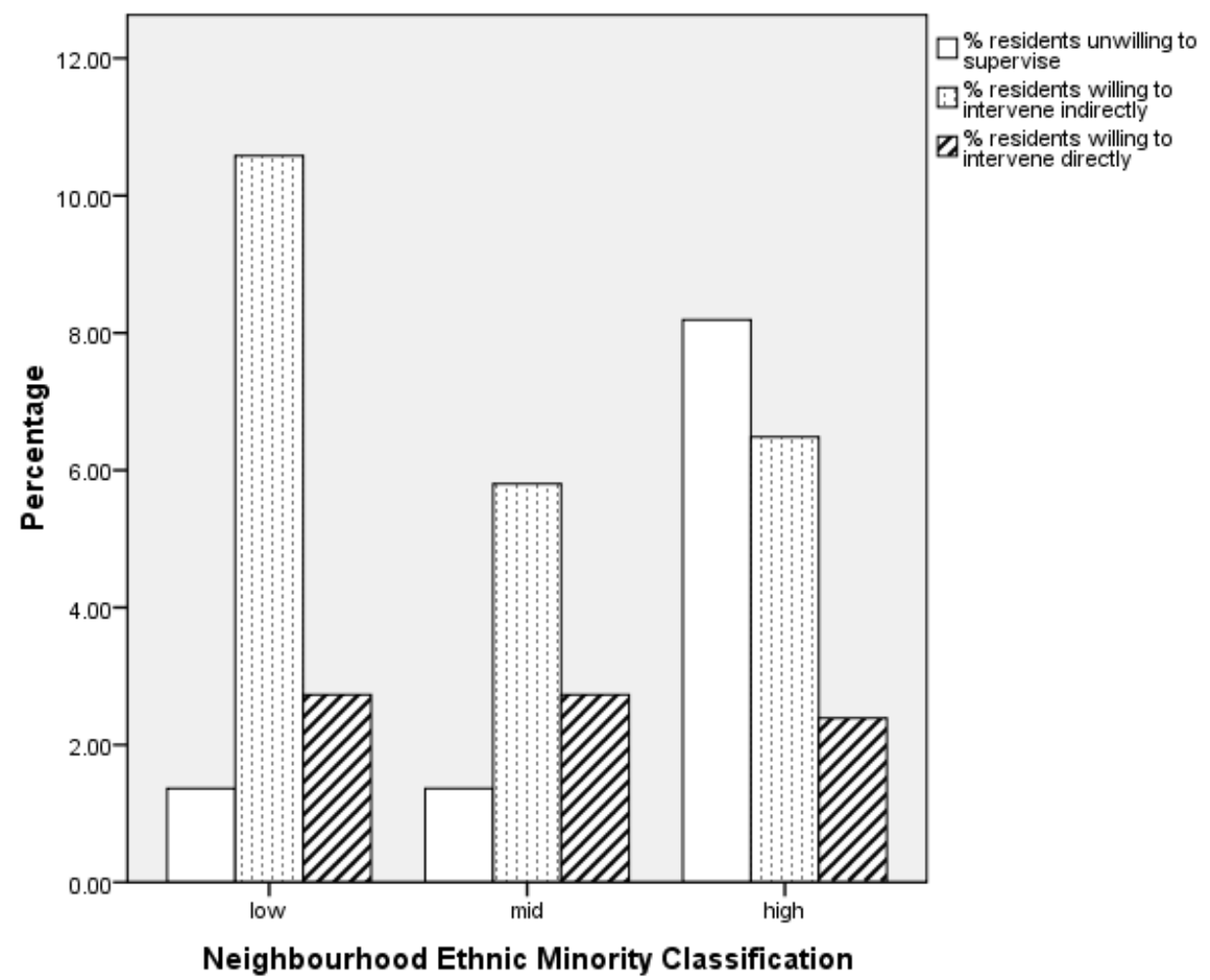


Figure 4: Data Display- Flow diagram of decision-making processes of available guardians

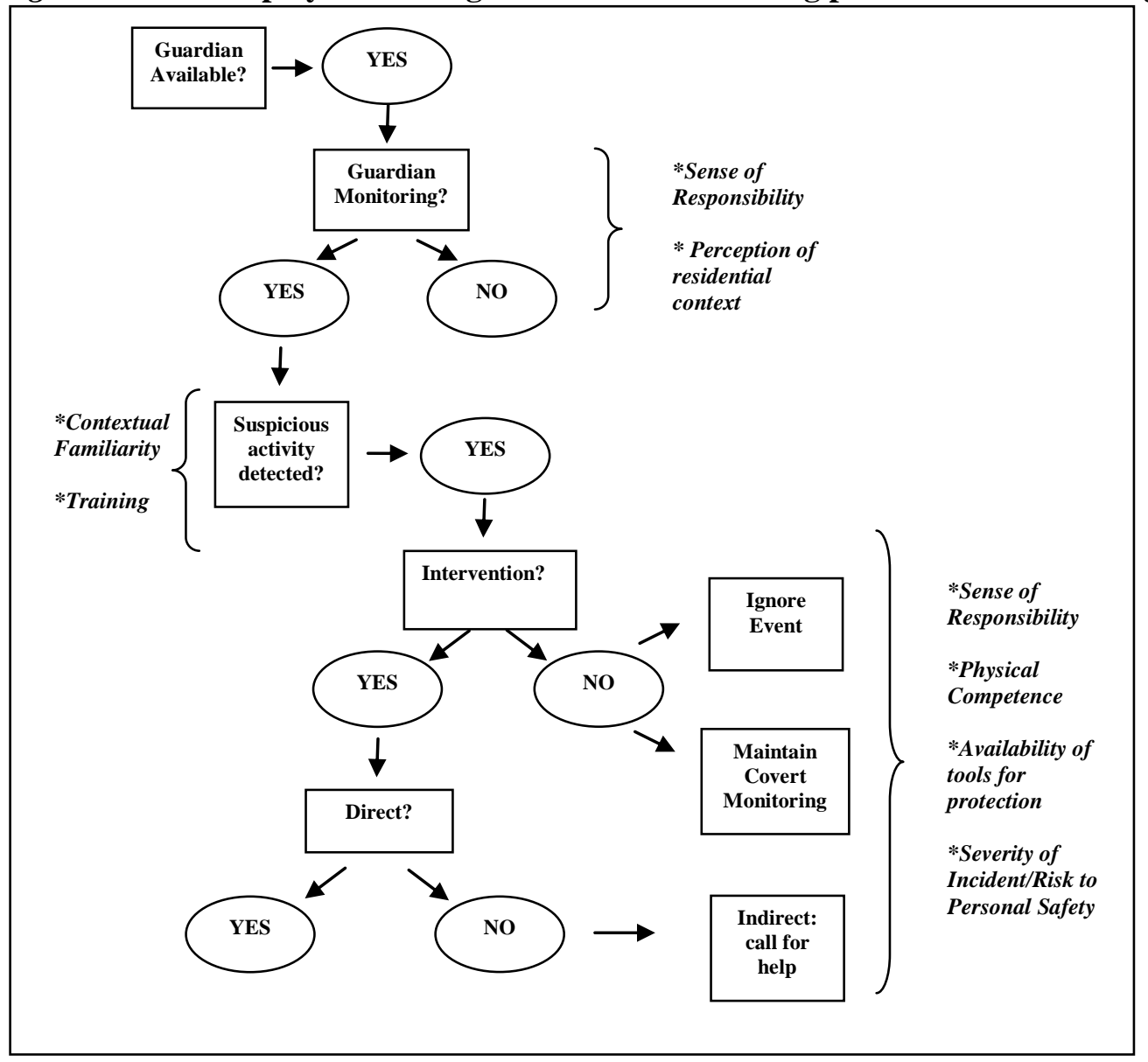

\section{Appendix 2: Categories derived from conceptually clustered responses from guardians}

\section{Anti-Social Behavior (47\%)}

○ "On evenings, there is a lot of drug-using and drinking, loud shouting on the streets. This makes me nervous."

○ "You see young people on drugs or alcohol misbehave sometimes."

○ "Rudeness, and displays of a lack of respect for others..."

○ "Wild and intimidating behavior of the young boys who hang out on the square..."

\section{Secretive Behavior (37\%)}


○ "Sneaky, inconspicuous behavior ...like hiding etc."

○ "I get suspicious...especially if I see people sneaking around, crouching behind bushes and so on."

○ “...covert, sneaky behavior..”

o “...especially if I see sneaky behavior, I pay attention. You can see it in how they look at you."

\begin{abstract}
Aimlessness (18\%)
○ ".. you see it in the attitude and a little when they just hang around aimlessly."

○ "you see it sometimes, a person that doesn't live here just hanging around."

○ "Men just hanging around for no reason...walking around aimlessly."

o "People who just hang around with nothing to do"
\end{abstract}

\title{
Nervous Response to Monitoring (12\%)
}

o "How they respond when you look at them-if they run away or cross to the other side of the street, or avoid your gaze."

○ "I look to see how people respond when I stare at them, when they see I am watching them, if they get nervous or so"

○ "...if they run when you look at them..."

o "...if they avoid eye contact when you look at them..."

\section{Eyeing Potential Targets (11\%)}

○ "If I see people looking into cars, or looking at bicycles..."

○ “When I see someone staring into property windows, I get suspicious.”

○ “...if I see someone standing and fiddling with a door. That's just strange to me."

○ “...peering through the windows of a house and looking at what's inside..." 